\title{
EXCENTRICIDADE E TRANSGRESSÃO DE GÊNERO NA AUTOBIOGRAFIA DE MARGARET SKINNIDER
}

\section{EXCENTRICITY AND GENDER \\ TRANSGRESSION IN MARGARET SKINNIDER'S AUTOBIOGRAPHY}

\author{
Raimundo Expedito dos Santos Sousa" \\ Adelaine LaGuardia**
}

Resumo: Mediante análise da autobiografia da militante feminista e nacionalista Margaret Skinnider, atuante no processo de descolonização irlandesa, investigamos, com base na teoria da performatividade, seu uso excêntrico e transgressivo da vestimenta na constituição performativa do gênero, sublinhando sua instrumentalização do vestuário em micro resistências operadas nos interstícios das tecnologias disciplinares. Atentos ao modo como Skinnider jogava com padrões de vestuário, demonstramos que a militante transgredia duplamente as normatividades de gênero, seja por uma condescendência estratégica na qual burlava códigos de feminilidade no ato mesmo de sua suposta iteração, seja pela prática da travestilidade, que lhe facultava uma constante flutuação entre os pólos masculinos e femininos.

Palavras-chave: Gênero. Performatividade. Margaret Skinnider.

AвSTRACT: Through the analysisof the autobiography of the feminist and nationalist militant Margaret Skinnider, who acted in the Irish decolonization process, this study based on performativity theory investigates her excentric and transgressive use of clothing in the performative constitution of gender, highlighting her instrumentalization of clothing in microrresistences in the interstices of disciplinary technologies. Attentive to the way Skinnider played with clothing patterns, the study demonstrates that the militant doubly transgressed gender normativities, either through as trategic condescendence in which she cheated codesof femininity in the very act of their supposed iteration, or through the practice of travestility, which favored a constant fluctuation between male and female poles.

KEYwords: Gender. Performativity. Margaret Skinnider.

\footnotetext{
"Doutorando em Teoria da Literatura e Literatura Comparada pela Universidade Federal de Minas Gerais; mestre em Estudos Literários pela Universidade Federal de São João del-Rei. E.mail: raimundo_sousa@terra.com.br "Doutora em Literatura Comparada pela Universidade Federal de Minas Gerais. E.mail: adelaineufsj@gmail.com
} 
O GÊNERO VESTUÁrio E O GÊNERO COMO VESTUÁRIO

Embora conceba a resistência como contraface primeira do poder, asseverando que onde houver este último aquela também se fará presente, Foucault (1976) se atém menos às formas de resistência do que ao modo por que operam os dispositivos disciplinares e às posições-de-sujeito que estes engendram. Dessa opção analítica resulta, segundo Hall (1996),

a formal account of the construction of subject positions within discourse while revealing little about why it is that certain individuals occupy some subject positions rather than others. By neglecting to analyse how the social positions of individuals interact with the construction of certain 'empty' discursive subject positions, Foucault reinscribes an antinomy between subject positions and the individuals who occupy them. Thus his archaeology provides a critical, but one-dimensional, formal account of the subject of discourse. Discursive subject positions become a priori categories which individuals seem to occupy in an unproblematic fashion (p. 10).

Ainda que cada arranjo social legitime determinados padrões identitários pela universalização de princípios mono central, a hegemonia, longe de absoluta, dá-se numa dinâmica entre norma e agência em que as formas de apropriação pelos atores podem tanto reproduzi-la, quando se conformam com as determinações advindas dos padrões centralizados, quanto desafiá-la, nos casos em que assumem um caráter ex-cêntrico. Porém, o descrédito com que geralmente tratamos as experiências "banais" não raro impossibilita a devida apreensão dessa potencialidade disruptiva, haja vista a análise de um eminente sociólogo acerca das implicações da moralidade sexual instituída pela Igreja católica na Irlanda. Seguro de que o monopólio moral eclesiástico intimidou a formação de dissidências sexuais no país até meados do século XX, Inglis (2005) superestima a normatividade, atribuindo-lhe um poder que, embora limitativo, não foi suficientemente implacável para impedir transgressões, e subestima as micro resistências, assegurando que "é difícil encontrar quaisquer vestígios de resistência ou desafio à ordem normativa existente" (p. 13; nossa tradução'). Ao restringir a possibilidade de mudança social ao domínio da macroestrutura, sua perspectiva desconsidera que tal mudança se constitui graças, também, à somatória de rupturas isoladas. Ora, porque alheio à alçada dos eventos que, monumentalizados, constituem a chamada História Oficial, o quotidiano é associado, no mais das vezes, a uma ciclicalidade de práticas repetitivas e, portanto, estáticas. Todavia, longe de restrito ao universo da rotina (repetição), o mesmo quotidiano constitui um campo aberto para o inusitado (ruptura) na medida em que, segundo de Certeau (1980), a subversão pode operar nos interstícios das tecnologias institucionais e

\footnotetext{
${ }^{1}$ Todas as traduções de citações em língua estrangeira são de nossa autoria. Em benefício da fluência textual, optamos por traduzir as citações diluídas no texto e, em prol da fidelidade às fontes, por manter na língua original as citações recuadas.
} 
dos discursos dominantes por meio de formas sub-reptícias de transgressão que jogam com os mecanismos disciplinares.

Uma forma de captar esse potencial excêntrico consiste em redimensionar a lente investigativa, somando-se ao foco nas instâncias repressivas a atenção também para o âmbito da "experiência vivida", conceito fenomenológico caro ao projeto inicial dos estudos culturais, a fim de observar possíveis fissuras e contradições na ordem instituída. Afinal, o panorama macrossociológico, ao priorizar os aparatos disciplinares, favorece um mapeamento da rede de discursos dominantes, mas, em contraposição, não apreende a complexidade das relações de gênero se tomado isoladamente - já estas se dão na dialética entre o nível macroestrutural (da regulação) e o nível microestrutural (da experiência).

Por sua vez, um modo de apreender as transgressões operadas no campo da experiência vivida consiste em atentar para a não-naturalidade do gênero, tal como fez Riviere (1929) de forma pioneira ao conceituar a feminilidade nos seguintes termos, a partir do caso de uma conferencista que exibia comportamentos exageradamente "femininos" como contrapeso de sua transgressão de gênero numa conjuntura desfavorável à atuação da mulher no espaço público:

Womanliness therefore could be assumed and worn as a mask, both to hide the possession of masculinity and to avert the reprisals expected if she was found to possess it [...]. The reader may now ask [...] where
I draw the line between genuine womanliness and the 'masquerade.' My suggestion is not, however, that there is any such difference; whether radical or superficial. They are the same thing (p. 38).

A intrigante sinonímia estabelecida pela psicanalista antecipa o desconstrutivismo ao sugerir que a feminilidade que a mulher supostamente arremeda é também uma simulação que, inexistente in natura, não passa de uma apropriação de padrões culturais como autoproteção numa organização social androcêntrica.

A pressuposição da teatralidade do gênero na noção de feminilidade como máscara tem inspirado feministas como Butler (1990), que, em formulação seminal para a teoria queer, compreende o gênero como efeito de atos performativos de cuja iteratividade depende a naturalização de determinados paradigmas culturais. Contudo, a mesma cadeia de repetição que naturaliza padrões de gênero pode atuar inversamente mediante performances que subvertem a ilusão de estabilidade identitária. Donde o caráter transgressivo da travestilidade, na qual o sujeito, ao trajarse parodicamente como o "sexo oposto", transgride representações de gênero e a própria equivalência entre sexo e gênero, já que a diferença entre a anatomia da/do drag e o gênero representado revela o caráter contingente $\mathrm{e}$ imitativo deste último, expondo como a identidade é constituída performativamente pelas próprias expressões que supostamente seriam sua exteriorização. 
Essa formulação tem recebido, ao lado de comentários elogiosos, severas críticas por passar ao largo das especificidades contextuais em que as performances de gênero se situam e, consequentemente, por não problematizar suas nuances e contradições. Namaste (1996), por exemplo, relaciona o textualismo de Butler a uma distorção da proposta inicial dos estudos culturais, que tinham em mira o campo da experiência como paradigma de estudo, e reclama que a teórica, no lugar de compreender como os conflitos de gênero sucedem no aqui-e-agora das relações sociais, restringe-se a significações textuais desprendidas de sua base material, numa perspectiva meramente ensaística e abstrata que perde de vista o horizonte interventivo.

Cientes tanto da pertinência conceitual da performatividade para o exame da construção social do gênero quanto, em contrapartida, da obliteração das relações materiais sob cuja base se instauram as práticas de significação como uma das limitações das metodologias textualistas, procuramos, neste trabalho, analisar a noção de performatividade a partir da "experiência vivida", a fim de explorar como os sujeitos tomam parte em sua formação identitária mediante suas práticas sociais. Para tanto, investigamos as formas de negociação empreendidas por mulheres que, apesar do empenho da intelligentsia nacionalista irlandesa em restringir seu agenciamento, atuaram no nacionalismo para além dos limites impostos ao seu gênero. Sem a pretensão de traçar um panorama geral da participação das mulheres no projeto nacional ${ }^{2}$, focalizamos especificamente o caso paradigmático da militante feminista e nacionalista Margaret Skinnider, observando, a partir dos registros memoriais contidos em sua autobiografia, Doing my bit for Ireland (1917), como sua agência, sob efeito da travestilidade, desmantelava não somente papéis de gênero como a própria noção de gênero.

EXCENTRECIDADE E TRANSGRESSÃO DE GÊNERO NA AUTOBIOGRAFIA DE MARGARET SKINNIDER

Emergente numa episteme calcada na obsessão por dicotomias de gênero sob influxo de uma cosmologia ocidental que polarizava o universo em dois domínios supostamente ontológicos, quais sejam, o masculino e o feminino, o imperialismo moderno se assentou em um regime de significação no qual praticamente tudo era submetido a uma taxonomia binária e classificado como masculino ou feminino, inclusive os países, e neste caso se reduziam ao binarismo heteronormativo e ao determinismo biológico complexas disparidades históricas, econômicas e culturais entre povos:

In figuring the conquerors as the exponents of a principle coded and celebrated as masculine (encompassing an aggressive will to historical progress, technical mastery and rational transcendence, et cetera), and the conquered as the embodiment of a principle

\footnotetext{
${ }^{2}$ Para tal, ver, dentre outros, Ward (1989), Murphy (1989) e McCoole (2003).
} 
stereotyped and discounted as female (encompassing a passive repose in organic cyclicality, affective immanence and domestic concerns, et cetera), imperialist discourse has inscribed a vicious symbolic circle in which sexual and socio-economic dominance reflect and authorize one another (VALENTE, 1994, p. 189).

De largo uso como aparato discursivo legitimador do projeto expansionista imperial, essa lógica binária disjuntiva teve recursividade particular na conquista da Irlanda, colônia europeia cuja especificidade etnogeográfica exigia um engenho particular na justificação moral para sua expropriação. Por conseguinte, se o imperialismo investiu na feminização dos colonizados com vistas à chancela de medidas interventivas e exploratórias, a resistência anticolonial, em posição estatuária desfavorável no embate geopolítico, viu-se forçada a estruturar sua agenda em torno do revide a essa estratégia de desempoderamento. Assim, preso a uma dialética na qual suas formas possíveis de autoinvenção se davam em necessária contraposição às imputações do discurso colonial e, portanto, prendiam-se a elas, o anticolonialismo irlandês fundamentou seu projeto de descolonização em rígidas assimetrias de gênero a fim de provar a virilidade dos homens nativos, instaurando um código de hipermasculinidade que demandava, em complemento, um código de hiperfeminilidade análogo. Portanto, o primado da remasculinização teve como corolário um efeito subtrativo na agência das mulheres a fim de que não eclipsassem o protagonismo masculino nem desestabili- zassem as balizas de gênero que o referendavam (cf. CAIRNS \& RICHARDS, 1988; HOWESS, 1998; VALENTE, 2011).

Todavia, diversas mulheres não apenas conseguiram ultrapassar o cordon sanitaire que cindia as esferas masculina e feminina como obtiveram êxito no Levante de 1916 como mensageiras, espiãs e transportadoras de armas e munições, já que, valendo-se do estigma de "sexo frágil", passavam despercebidas pelas tropas inglesas por não levantarem suspeitas de engajamento no nacionalismo militar. Assim, sob seus vestidos e saias, moças aparentemente inofensivas estabeleciam contato entre os postos distribuídos em Dublin, transportando desde documentos confidenciais e grandes somas de dinheiro até armas e munições (CURTIS, 1994). Quando da invasão e inspeção de sua casa por soldados britânicos, Kathleen Clarke (1991), zeladora das finanças do Irish Republican Brotherhood, disfarçou o medo encarnando um estereótipo de feminilidade em uma cena típica de comédia policial que ilustra a teatralidade do uso do gênero na subversão da feminilidade pela própria feminilidade: "A fim de mostrar-lhes o quão pouco suas ações me preocupavam, peguei um lenço [] que eu vinha fazendo e fiquei trabalhando nele durante toda a busca (p. 84).

No entanto, quem melhor explorou a potencialidade disruptiva da performatividade de gênero foi a escocesa Margaret Skinnider (1893-1971), que, tendo aprendido a atirar em um clube de artilharia criado pelos britânicos "para que 
as mulheres pudessem ajudar na defesa do Império (SKINNIDER, 191733, p. 6), testaria seu aprendizado marcial contra o próprio império. Convidada por Constance Markievicz a colaborar no Levante de 1916, a suffragette e integrante da Cumann na mBan de Glasgow desembarcou na ilha armada literalmente dos pés à cabeça, usando seu vestuário "feminino" como suporte para materiais bélicos: "Em meu chapéu eu estava levando [...] detonadores para bombas e os fios estavam enrolados em torno de mim sob o meu casaco" (DMBI, 9).

$\mathrm{Na}$ casa de sua mentora, Skinnider notou uma variedade de trajes teatrais usados tanto como caracterização por atores quanto como disfarce por suffragettes e líderes trabalhistas no encalço da polícia. Essa dupla utilidade das roupas em performances teatrais e no uso, não menos teatral, como forma de transgressão de gênero e de classe parece tê-la inspirado a explorar o recurso pragmático-funcional da travestilidade. Assim, a voluntária arregimentada para atuar como mensageira se mostrou hábil também para outra função:

When I told Madam [Markievicz] I could pass as a boy, even if it came to wrestling or whistling, she tried me out by putting me into a boy's suit, a Fianna uniform. She placed me under the care of one of her boys to whom she explained I was a girl, but that, since it might be necessary some day to disguise me as a boy, she wanted to find whether I could escape detection.

\footnotetext{
${ }^{3}$ Doravante o texto será referenciado pela abreviação DMBI seguida do número da página.
}

[...] We went out, joined the other Fianna, and walked about the streets whistling rebel tunes (DMBI, 22-23).

Incumbida de duas funções que a inscreviam em papéis de gênero duais, Skinnider atuaria (em sentido teatral) ora como mulher/mensageira, ora como homem/fuzileiro, devendo ser ora "feminina" o bastante para executar suas operações de espionagem e transporte clandestino sem levantar suspeitas e ora suficientemente "masculina" para convencer seus pares de que era um deles. Nessa alternância de funções, a troca de gênero (genre) vestuário constituía um rito de passagem que implicava também mudança de gênero (gender):

Whenever I was called down to carry a despatch (sic), I took off my uniform, put on my gray dress and hat, and went out the side door of the college with my message. As soon as I returned, I slipped back into my uniform and joined the firing-squad (DMBI, 138).

Essa transformação ritualística, que aponta duas cadeias de repetições antitéticas, evidencia como o gênero, literalmente, vive de aparências, pois não apenas se constitui pelo vestuário como ele próprio é um vestuário enquanto inscrição cultural. Ao assumir transidentidades cambiantes numa constante flutuação por categorias que evidencia a insustentabilidade do binarismo ontológico homem/mulher, Skinnider expõe a contingência de categorias de gênero cuja suposta diferença ontológica se resume a convenções sociais materializadas 
no vestuário. Assim, o caráter paródico de suas performances aponta a natureza artificial do próprio gênero, como se nota na fotografia (Fig. 1) em que a ativista parodia o estereótipo de masculinidade, numa versão superlativa do masculino, posando com as pernas entreabertas, as mãos enfiadas nos bolsos e um charuto na boca.

Ao tempo em que aparentemente reforçava a cultura dominante, Skinnider se inseria numa contracultura que a desafiava pela transgressão paródica do dimorfismo masculino/feminino. Ao cumprir uma de suas missões noturnas, despertou a curiosidade de um policial que, no entanto, identificou-a como apenas uma jovem indefesa:

A policeman came slowly toward me. He had his dark-lantern and, catching sight of me, flashed it in my face. He stared, but said nothing. No doubt he was wondering what a decently dressed girl was doing in that part of town at such an hour. I watched him as closely as he watched me. He caught sight of my string, I intended to give three jerks, and, at the same moment, throw pepper in his face [...]. But he did not notice the string, and passed on (DMBI, 51).

A mesma máscara de feminilidade que intriga o policial o despista de examiná-la atentamente, pois a transgressão espaçotemporal é contrabalançada pelo vestuário, que no mapa conceitual do guarda a reposiciona em seu lugar de gênero como respeitável professora de classe média. Pelo tom irônico de sua autodescrição como "uma moça decentemente vestida",
Skinnider parece tão crítica quanto à natureza prescritiva da feminilidade que a utiliza como recurso, de modo que a aparente reverência constitui uma forma de transgressão na qual, ao vestir a máscara, ela desmascara convenções. Assim, servindo-se da estética como transgressão, Skinnider se mostra obediente aos preceitos de gênero pela incorporação de uma feminilidade respeitável que, paradoxalmente, permitelhe desrespeitá-la e, sob a aparente ingenuidade feminina, vigia sem ser notada, tal como quando passa despercebida por um policial: "Ele não prestou atenção em mim; eu era apenas uma garota de bicicleta. Mas eu o observei bem de perto" (DMBI, 95).

Seu uso consciente da feminilidade como recurso é notável na cena cinematográfica em que Skinnider se vale de um truque "feminino" para induzir um rapaz a ajudá-la no reconhecimento do território onde se situariam os barracões:

When I reached the spot where I thought the magazine ought to be, I took my handkerchief and let it blow - accidentally, of course - over this outer wall. A passing boy gallantly offered to get it for me. Being a woman and naturally curious, I found it necessary to pull myself up on tiptoe to watch him as he climbed over the wall. The ground between the two walls had not been paved, but was of soft earth. I had seen enough. Thanking the boy, I put my handkerchief carefully into my pocket so as not to trouble any one else by making them climb about on Dublin walls, and went on my way (DMBI, 40-41). 
Pela ironia com que se refere a estereótipos de gênero, a militante republicana deixa claro que, ao invés de considerar a feminilidade uma essência da qual a mulher se vale quando conveniente, considera-a uma fabricação cultural que só produz efeitos de sentido pela repetição. De fato, numa perspectiva foucaultiana de que o poder, longe de centralizado numa instância dominante, encontrase capilarmente espalhado pelo tecido social e, portanto, onipresente de forma multidirecional na dinâmica das relações sociais, mulheres como Skinnider obtinham empoderamento não por reproduzir acriticamente a ordem vigente, mas por trapaceá-la mediante uma condescendência estratégica que Bhabha (1985), referindo-se à agência do sujeito colonizado, denomina civilidade dissimulada. Se não podiam confrontar radicalmente o patriarcado, tais mulheres empreendiam microrresistências ao assumir identidades provisórias nas quais o repertório vestuário, sob o aparente reforço de códigos de gênero, servia como recurso para a transgressão de limites físicos e simbólicos, resultando que suas performances subvertiam a norma no ato mesmo de sua suposta iteração. Portanto, mesmo a adequação ao padrão de feminilidade pode ser disruptiva enquanto artificialidade calculada, pois, ao aparentemente se submeterem aos códigos de gênero dominantes pelo vestuário "bemcomportado", tais mulheres desnudavam em seu vestuário a estrutura imitativa e contingente do gênero, embaralhando a polaridade entre conformação e resistência.
Ao arremedar o sistema cultural hegemônico, Skinnider se engajava numa dinâmica de conformação e resistência na qual, apropriando-se dos repertórios disponíveis, participava de sua construção de gênero em vez de se enquadrar acriticamente em posições-de-sujeito. Portanto, a forma como essa e outras mensageiras e espiãs vestiam a feminilidade como máscara contradiz o argumento, sustentado por Irigaray (1985, 1989), de que tal recurso evidencia o status da mulher como espetáculo, não como expectadora, como objeto de desejo, não como sujeito desejante, configurando uma forma de retificação na qual esta usufrui alguma aquiescência social à custa da satisfação de fantasias masculinas e adequação a um sistema de valores que não o seu, anulando-se e anulando seu próprio desejo. Ora, se, por um lado, a máscara pressupõe mise-en-scène para um expectador, por outro encerra um jogo de simulação e dissimulação que permite ver escondendo-se.

Mensageiras e espiãs como Skinnider também desconstroem a tendência do feminismo radical à vitimização da mulher pela identificação dos padrões estéticos como dispositivos de controle institucionalizados cuja convergência entre interesses capitalistas e patriarcais a aprisiona à condição ornamental, simultaneamente impelindo-a ao consumo e inscrevendo-a como mercadoria dependente da aparência para atração do desejo masculinot. Ao desconsiderar o potencial de agência da mulher na forma como (in) veste suas roupas, tal perspectiva incorre na mesma subestimação adorniana

${ }^{4}$ Para uma crítica a essa tendência, ver Felski (1995). 
da possibilidade negociativa dos consumidores frente à Indústria Cultural, cujas imposições seriam introjetadas acriticamente pela massa concebida como receptáculo passivo da ingerência do poder, e recai, ainda, no mesmo sexismo patriarcal que codifica a mulher como passiva, ingênua e vulnerável. Quando, em vez de indagarmos o que as normatividades de gênero fazem das mulheres, reformulamos a questão para o que estas fazem com o que tais normatividades procuram fazer delas, encontramos formas de resistência nas franjas das próprias normas, pois os significados que atribuem ao vestuário não são necessariamente aqueles determinados pela ideologia de gênero. ${ }^{5}$

\section{CONSIDEREÇÕES FINAIS}

$\mathrm{Na}$ Irlanda, o anticolonialismo constituiu, a rigor, um corolário ideológico do próprio colonialismo, na medida em que respondia à economia maniqueísta que distinguia a virilidade imperial e a feminilidade colonial pelo imperativo de resgate da hombridade gaélica, incorrendo em semelhante maniqueísmo ao instaurar uma fixação obsessivo-compulsiva pela distinção entre masculinidade e feminilidade no ordenamento social e simbólico irlandês. Ora, uma vez que a masculinidade hegemônica se define em relação oposicional e complementar com a feminilidade e, portanto,

\footnotetext{
${ }^{5}$ Relação similar ao binômio codificação/decodificação tomado por Hall (1973) para argumentar que os significados idealizados pelos produtores midiáticos não são necessariamente os mesmos recebidos pelos consumidores, pois estes os ressignificam a partir de seu próprio contexto de experiência.
}

qualquer alteração nos padrões desta última desestabiliza os referenciais da primeira, no projeto nacional irlandês as mulheres eram encurraladas sob diversas tecnologias disciplinares com vistas à circunscrição de suas possibilidades de agência.

Todavia, mulheres como Margaret Skinnider dão mostras de que o mesmo nacionalismo que limitava sua atuação lhes permitia exercer alguma forma de empoderamento, quer pela apropriação disruptiva que subvertia os códigos de feminilidade no ato mesmo de sua aparente iteração, quer pelo efeito da travestilidade que facultava um movimento transidentitário revelador da estrutura contingente e imitativa do gênero. De fato, a configuração monológica desse projeto foi comprometida por suas próprias contradições constitutivas, uma vez que sua agenda, embora androcêntrica era desafiada por microresistências operadas nos interstícios das tecnologias disciplinares por mulheres cujas performatividades de gênero jogavam com os códigos de feminilidade instituídos.

\section{REFERÊNCIAS}

BHABHA, H. K. Sly civility. October, v. 34, p. 71-80, Outono, 1985.

BUTLER, J. Gender trouble: feminism and the subversion of identity. New York: Routledge, 1990.

CAIRNS, D.; RICHARDS, S. Writing Ireland: colonialism, nationalism, and culture. New York: St. Martin's, 1988.

CLARKE, K. Revolutionary woman: my fight for Ireland's freedom. Ed. Helen Litton Dublin: The O'Brien Press, 1991. 
CURTIS, L. The cause of Ireland. Belfast: Beyond the Pale Publications, 1994.

DE CERTEAU, M. L'invention du quotidien: 1 . Arts de faire. Paris: Gallimard, 1980.

FELSKI, R. The gender of modernity. Cambridge: Harvard University Press, 1995.

FOUCAULT, M. Histoire de la sexualité, v. I: La volonté de savoir. Paris: Gallimard, 1976.

HALL, S. Encoding and decoding in the television discourse. Birmingham: University of Birmingham Centre for Contemporary Cultural Studies, 1973.

HALL, S. Introduction: Who needs identity? In: HALL, Stuart; DU GAY, Paul (eds.). Questions of cultural identity. London: Sage, 1996, p. 1-17.

HOWES, M. Yeats's nations: gender, class, and irishness. Cambridge: Cambridge University Press, 1998.

INGLIS, T. Origins and legacies of Irish prudery: sexuality and social control in modern Ireland. Éire-Ireland, v. 40, n. 3\&4, p. 9-37, 2005.

IRIGARAY, L. Masquerade reconsidered: further thoughts on the female spectator. Discourse, v. 11, n. 1, p. 42-54, 1989.

IRIGARAY, L. Speculum of the other woman. Ithaca: Cornell University Press, 1985.

MCCOOLE, S. No ordinary women: Irish female activists in the revolutionary years, 1900-1923. Madison: University of Wisconsin Press, 2003.

MURPHY, C. The women's suffrage movement and Irish society in the early twentieth century. New York: Harvester Wheatsheaf, 1989.

NAMASTE, K. "Tragic Misreadings": queer theory's erasure of transgender subjectivity. In: BEEMYN, B.; ELIASON, M. (eds.).
Queer studies: a lesbian, gay, bisexual, and transgender anthology. New York: New York University Press, 1996, p. 183-203.

RIVIERE, J. Womanliness as masquerade. The international journal of psychoanalysis, $\mathrm{v}$. 10, p. 303-313, 1929.

SKINNIDER, M. Doing my bit for Ireland. New York: The Century CO., 1917.

VALENTE, J. The myth of manliness in Irish national culture, 1880-1922. Urbana: University of Illinois Press, 2011.

VALENTE, J. The myth of sovereignty: gender in the literature of Irish nationalism. ELH, v. 61, n. 1, p. 189-210, 1994.

WARD, M. Unmanageable revolutionaries: women and Irish nationalism. London: Pluto Press, 1989.

Recebido para publicação em 17 de Jul. de 2014. Aceito para publicação em 20 de Set. 2014. 